\title{
Agrotóxicos em mananciais superficiais no Assentamento Antônio Conselheiro, Mato Grosso
}

A contaminação da água utilizada para o consumo humano por agrotóxicos é preocupante e tem sido verificada em diversos estudos. Neste sentido, o objetivo deste trabalho foi avaliar a presença de um fungicida (protioconazol) e um herbicida (2,4-D) na água dos principais mananciais superficiais disponíveis no Assentamento Antônio Conselheiro (AAC), localizado no estado de Mato Grosso. As coletas foram realizadas no dia 5 de maio de 2015 em um ponto na entrada e outro na saída do AAC em cada manancial. As amostras de água foram analisadas por cromatografia líquida (HPLC) em laboratório credenciado. Os valores obtidos $(<0,001 \mu \mathrm{g} L-1)$ encontram-se abaixo do máximo permitido na legislação em todos os pontos de coleta e indicam que, caso exista contaminação, a concentração de 2,4-D e protioconazol é muito baixa e, por isso, pode não representar risco à saúde dos usuários da água dos rios Juba e Sepotuba e do ribeirão Tarumã. Tais resultados são importantes, pois os moradores do AAC fazem uso da água desses mananciais para os mais diversos fins, inclusive para o consumo humano e dessedentação de animais. Além disso, a pesca para complementação da alimentação é uma prática comum na região e pode ser comprometida em decorrência de contaminação da água por agroquímicos.

Palavras-chave: Contaminação Hídrica; Agroquímico; Desenvolvimento Social; Agricultura Familiar; Qualidade Ambiental.

\section{Pesticide in surface sources in the Antônio Conselheiro settlement, Mato Grosso}

\begin{abstract}
Contamination of water used for human consumption by pesticides is worrying and has been verified in several studies. So, the objective of this study was to evaluate the presence of a fungicide (prothioconazole) and a herbicide (2,4-D) in the water of the main surface water sources available on the Settlement Antônio Conselheiro (AAC), located on state of Mato Grosso. Samples were collected on May 5, 2015 at the entrance and exit of the AAC in each stock. The water samples were analysed by high performance liquid chromatography (HPLC) by an accredited laboratory. The values obtained $(<0.001 \mu \mathrm{g} L-1)$ are below the maximum allowed by law and indicated that, if there is contamination, the concentration of 2,4-D and prothioconazole is very low and therefore may not constitute a risk the health of users of water from the rivers Juba and Sepotuba and Tarumã stream. These results are important because the residents of AAC make use of water from these sources for various purposes, including for human consumption and watering livestock. In addition, the fishing for completion of the feed is a common practice in the region and can be compromised due to water contamination by agricultural chemicals.
\end{abstract}

Keywords: Water Contamination; Agrochemical; Social Development; Family Farming; Environmental Quality.

\section{Topic: Recursos Hídricos}

Reviewed anonymously in the process of blind peer.

Thaís Vasconcelos Silva

Universidade do Estado de Mato Grosso

http://lattes.cnpq.br/2413076734012286

thais.silva@jna.ifmt.edu.br

Tadeu Miranda de Queiroz

Universidade de São Paulo

http://lattes.cnpq.br/2582121765769124

tdmqueiroz@yahoo.com.br
Received: 09/12/2015

Approved: 20/12/2015

\section{Referencing this:}

SILVA, T. V.; QUEIROZ, T. M.. Agrotóxicos em mananciais superficiais no Assentamento Antônio Conselheiro, Mato Grosso. Revista IberoAmericana de Ciências Ambientais, v.7, n.1, p.235-243, 2016. DOI: http://doi.org/10.6008/SPC2179-6858.2016.001.0020 


\section{INTRODUÇÃO}

De toda a água doce disponível em mananciais superficiais no planeta, $12 \%$ está localizada em território brasileiro (BRASIL, 2010). Apesar da grande disponibilidade relativa, o Brasil enfrenta situações de escassez em algumas regiões devido ao déficit hídrico e em outras em decorrência da má qualidade. A qualidade da água, fator decisivo para sua utilização, é fundamental para a sua classificação, por exemplo, permitindo a aplicação de uma água imprópria para consumo humano em atividades menos exigentes, como a agricultura.

A qualidade da água está intimamente relacionada com aspectos naturais, como características do solo e vegetação, e decorrentes das atividades antrópicas, como despejos de esgotos domésticos e industriais, uso de fertilizantes e agroquímicos na agricultura, dentre outras. $\mathrm{O}$ uso de produtos químicos para controle de pragas integra o pacote tecnológico da produção agrícola e faz do Brasil o maior consumidor mundial de agroquímicos (BRASIL, 2015), estando o estado de Mato Grosso na liderança do ranking nacional.

A utilização em larga escala de agrotóxicos pode promover o seu transporte para o lençol freático ou diretamente para os cursos d'água alterando os padrões de qualidade. A presença de compostos químicos em concentrações acima do permitido pode causar intoxicação e doenças ou impedir o uso da água em atividades específicas, como, por exemplo, o abastecimento para consumo humano.

A contaminação da água por agrotóxicos foi objeto de estudo em diversas localidades, como Lucas do Rio Verde e Campo Verde, Mato Grosso (DORES; DE-LAMONICA-FREIRE, 2001; MOREIRA et al., 2012), Nova Friburgo, Rio de Janeiro (MOREIRA et al., 2002; GASPARINI; FREITAS, 2013), Rondinha, Rio Grande do Sul (GRIZA et al., 2008), dentre outros. Embora estes estudos tenham sido realizados em localidades distintas pode-se observar que em todos os locais onde foi detectada a presença de um agrotóxico houve a ocorrência de vários, uma vez que o combate a pragas e doenças demanda o uso de uma variedade de produtos. Neste sentido, observa-se que a quantificação de agrotóxicos chave pode indicar a contaminação por outros, orientando estudos mais abrangentes.

A preocupação quanto à contaminação em decorrência do uso de agrotóxicos é maior quando a água é utilizada para o consumo humano. A Organização Mundial de Saúde (OMS) estabelece limites para a presença de agrotóxicos na água com base em estudos epidemiológicos e toxicológicos, sendo que para o 2,4-D a concentração máxima permitida é de $30 \mu \mathrm{g} \mathrm{L}^{-1}$ (OMS, 2011). A Environmental Protection Agency (EPA), agência norte-americana responsável pela proteção da saúde humana e do ambiente, estabelece a concentração de $70 \mu \mathrm{g} \mathrm{L}^{-1}$ como limite máximo para o 2,4-D (EPA, 2014). O Health Canada, departamento do governo federal responsável por auxiliar os canadenses a manter e melhorar a sua saúde, indica que a concentração máxima aceitável para o 2,4-D em água para consumo é de $100 \mu \mathrm{g} \mathrm{L}^{-1}$ (HC, 2009). A União Europeia adotou como padrão geral de qualidade da água para consumo humano o limite de até $0,5 \mu \mathrm{g} \mathrm{L}^{-1}$ para o conjunto de agrotóxicos encontrados e de $0,1 \mu \mathrm{g} \mathrm{L}^{-1}$ individualmente (UE, 1998).

No Brasil, a Portaria $n^{\circ} 2.914$ do Ministério da Saúde (BRASIL, 2011), que dispõe sobre procedimentos de controle e vigilância da qualidade da água para consumo humano, indica como valor máximo permitido 
para o 2,4-D de $30 \mu \mathrm{g} \mathrm{L}^{-1}$. Segundo a Resolução $\mathrm{n}^{\circ} 357$ do Conselho Nacional de Meio Ambiente (CONAMA) (BRASIL, 2005), as águas doces enquadradas na classe I, que podem ser destinadas ao abastecimento para consumo humano, após tratamento simplificado, bem como para a irrigação de hortaliças, podem conter no máximo $4,0 \mu \mathrm{g} \mathrm{L}^{-1}$ de 2,4-D.

Nas áreas de agricultura de grande porte as principais culturas são cana-de-açúcar, milho, soja e algodão dentre as quais cita-se o uso do 2,4-D no combate a plantas daninhas e do protioconazol para o controle da ferrugem na cultura da soja. Na área do Assentamento Antônio Conselheiro (AAC) as principais atividades desenvolvidas são a criação de animais e a agricultura (culturas temporárias e perenes diversificadas). Os assentados relatam o uso do 2,4-D em atividades de rotina como o manejo do pasto e a capina química. Entretanto, o uso indiscriminado de produtos químicos pode ter consequências danosas ao meio ambiente, como a contaminação de fontes de água. Em uma das visitas ao AAC observou-se a mortandade de peixes em tanques de criação que, segundo relato do proprietário, poderia estar associada ao uso de agrotóxicos na propriedade adjacente.

Além da agricultura e pecuária, os assentados fazem uso da água para o consumo e o seu tratamento é mínimo ou inexistente. Este fato demonstra a importância de estudos de avaliação da qualidade da água consumida pela população do assentamento, mas também pelo fato da água do rio Sepotuba desaguar no rio Paraguai, principal manancial que forma o Pantanal. Ademais, não há registros na literatura de estudos desta natureza nestes mananciais.

Neste sentido, o objetivo do trabalho foi avaliar a presença de um fungicida (protioconazol) e um herbicida (2,4-D) na água dos principais mananciais superficiais disponíveis no Assentamento Antônio Conselheiro.

\section{METODOLOGIA}

\section{Área de Estudo}

O estudo foi realizado nos rios Sepotuba e Juba e no ribeirão Tarumã que são os principais mananciais superficiais da área do AAC, localizada entre as coordenadas geográficas 14 e $15^{\circ} \mathrm{S}$ de latitude e 59 a $57^{\circ} \mathrm{W}$ de longitude e que abrange parte dos municípios de Tangará da Serra, Barra do Bugres e Nova Olímpia, no estado de Mato Grosso (Figura 1).

De acordo com IBGE (2004a), os mananciais fazem parte do bioma Amazônia, com vegetação predominante do tipo Floresta Estacional Semidecidual (IBGE, 2004b). Esta área de bioma Amazônia se encontra circundada, quase que na totalidade, pelo bioma Cerrado, o que reforça as características de área de transição. Assim, os mananciais estudados encontram-se na área de influência dos biomas Amazônia e Cerrado. Ademais, o rio Juba e o ribeirão Tarumã são contribuintes do rio Sepotuba que é afluente do rio Paraguai, o principal curso de água que banha o Pantanal.

O clima da região é denominado Tropical Úmido Megatérmico (Awa), segundo a classificação de Köppen, caracterizado por ser chuvoso no verão e seco no inverno, com altas temperaturas. A região de 
Tangará da Serra apresenta temperatura média anual de 24ํㅡ, precipitação de $1500 \mathrm{~mm}$ e umidade relativa do ar de 70 a $80 \%$ (Dallacort et al., 2010).

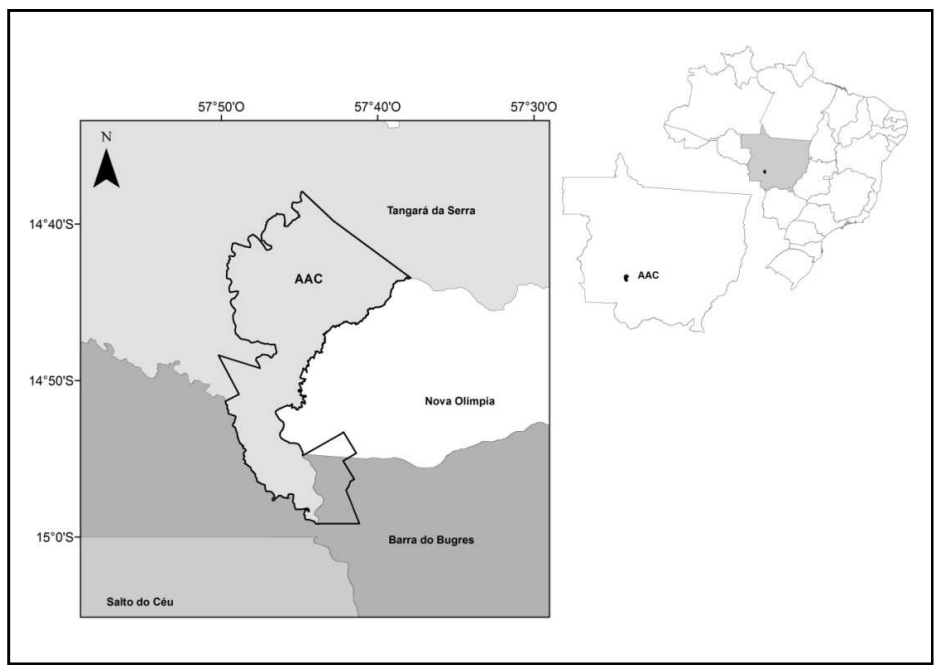

Figura 1: Localização da área do AAC.

Os solos da região são compostos por Latossolos Amarelos Distróficos, Neossolos Quartzarênicos Órticos e Flúvicos Distróficos, Argissolos Vermelhos Eutróficos e Vermelhos-Amarelos Distróficos e Cambissolos Háplicos Distróficos (IBGE, 2011), todos de boa drenagem.

\section{Os Mananciais e seu Entorno}

O rio Sepotuba nasce na encosta da Serra dos Parecis sendo a parte alta da bacia caracterizada por empreendimentos agrícolas que fazem uso de tecnologias modernas, como a utilização de substâncias químicas para o controle de pragas e doenças. O AAC está localizado na porção média da bacia.

O rio Juba tem suas nascentes no alto da Serra de Parecis, região com intenso uso de tecnologias de produção na agricultura. Na parte média, os empreendimentos têm foco no reflorestamento de teca, produção de frutas e criação de animais em confinamento e há unidades de geração de energia. O AAC está localizado no baixo rio Juba onde este deságua no rio Sepotuba.

O ribeirão Tarumã tem suas nascentes na Serra de Tapirapuã em áreas de grandes plantios de soja e cana-de-açúcar. A leste recebe as contribuições de áreas nas quais a criação de gado é a atividade predominante. $\mathrm{Na}$ área do $\mathrm{AAC}$ pertencente à bacia do ribeirão Tarumã é caracterizada por relevo plano, solos rasos e pouco estruturados com afloramentos rochosos em diversos locais, o que restringe o desenvolvimento de algumas atividades. Assim, a criação de gado é comum nestas áreas.

\section{Coleta e Análise de Água}

A determinação dos pontos de coletas foi feita com o auxílio de mapas e visitas ao local. Para verificar a contribuição das atividades agrícolas para a qualidade da água tomou-se um ponto de coleta antes da entrada e um na saída de cada manancial na área do AAC, conforme representado na Figura 2. 


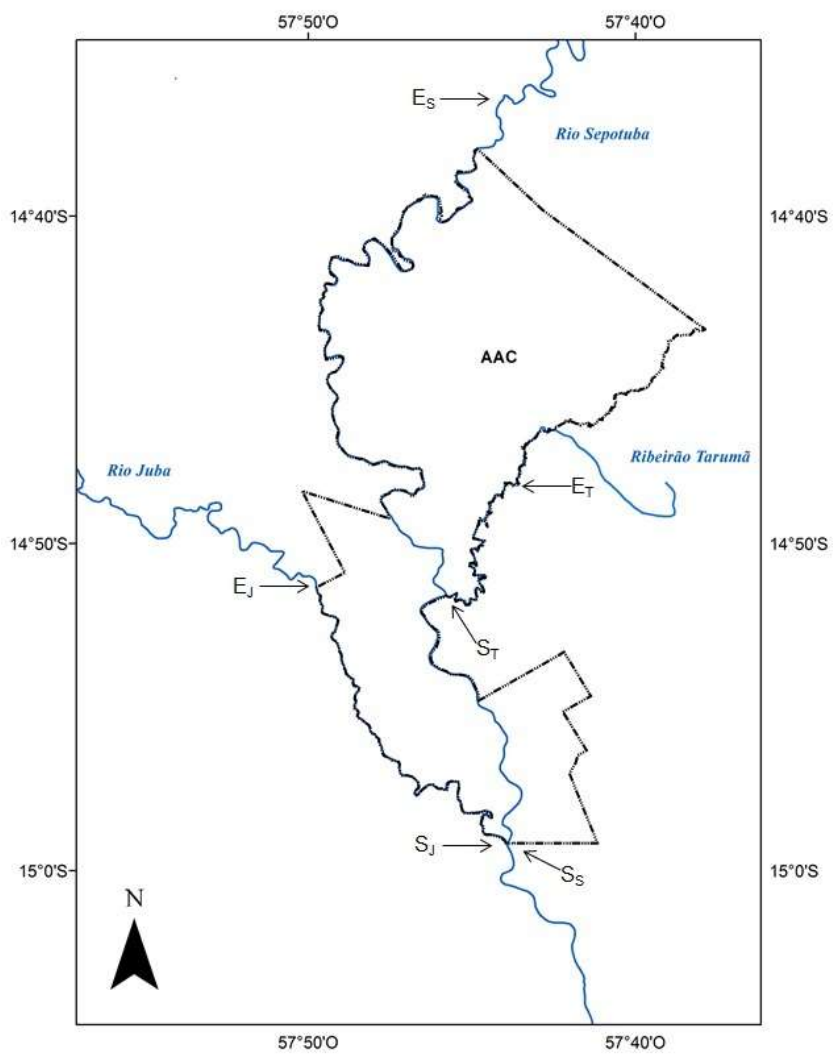

Figura 2: Localização dos pontos de coleta na entrada (E) e saída (S) da área do AAC nos rios Sepotuba (S), Juba (J) e ribeirão Tarumã $(T)$.

As amostras de água foram coletadas em recipientes plásticos com capacidade para um litro e protegidos da incidência de luz. As coletas foram realizadas pela manhã, à margem do manancial e os recipientes foram acondicionados em caixas térmicas contendo gelo seco para preservar as amostras no transporte do campo ao laboratório.

As análises de determinação dos princípios ativos foram realizadas de acordo com Standard for the Examination of Water and Wastewater por laboratório credenciado e acreditado pelo INMETRO. O custo das análises para detecção de princípios ativos de agrotóxicos em água é elevado, o que inviabilizou a realização de outros ensaios.

\section{RESULTADOS E DISCUSSÃO}

Os resultados negativos, considerando o limite mínimo de detecção do equipamento, para concentrações dos agrotóxicos não permitiram a utilização de qualquer ferramenta estatística para tratamento dos dados. As concentrações medidas nas amostras encaminhadas ao laboratório estão relacionadas na Tabela 1.

Tabela 1: Concentração de 2,4-D e protioconazol, nos três mananciais superficiais avaliados e limites estabelecidos em normativas.

\begin{tabular}{cccc}
\hline Manancial & Ponto de coleta & Concentração de 2,4-D & Concentração de protioconazol \\
\hline \multirow{2}{*}{ Rio Sepotuba } & Entrada & $<0,001$ & $<0,001$ \\
& Saída & $<0,001$ & $<0,001$ \\
Rio Juba & Entrada & $<0,001$ & $<0,001$ \\
Rio Tarumã & Saída & $<0,001$ & $<0,001$ \\
\end{tabular}




\begin{tabular}{cc} 
Saída & $<0,001$ \\
\hline Portaria MS n ${ }^{\circ}$ 2.914 & 30 \\
Resolução $n^{\circ}$ 357 Conama & 4 \\
União Europeia (UE) & 0,1 \\
Organização Mundial de Saúde (OMS) & 30 \\
Environmental Protection Agency (EPA) & 70 \\
Health Canada (HC) & 100 \\
\hline
\end{tabular}

Valores em $\mu \mathrm{g} \mathrm{L}{ }^{-1}$ Health Canada (HC)

Os resultados obtidos indicam que possivelmente as atividades agrícolas não estão impactando a qualidade da água dos mananciais avaliados. Como não foi identificada concentração de 2,4-D e protioconazol considerando o limite de detecção do equipamento, caso haja a contaminação, a concentração é muito pequena e não pode ser detectada neste ensaio.

A nomenclatura 2,4-D é a forma simplificada de denominação do ácido diclorofenoxiacético disponível em formulações aminas (não voláteis) ou ésteres (voláteis) que são rapidamente hidrolisados para a forma de ácido livre na água, o que pode explicar a não detecção de 2,4-D nas amostras. De forma análoga, a presença de resíduos de 2,4-D não foi detectada em estudo realizado nas águas do córrego Espraiado, local de recarga do aquífero Guarani (CERDEIRA et al., 2002).

Entretanto, a avaliação realizada na bacia do rio Itajaí em Santa Catarina verificou concentrações de até $74,4 \mu \mathrm{g} \mathrm{L}^{-1}$ de 2,4-D em águas superficiais, ultrapassando os limites estabelecidos pela legislação brasileira (PINHEIRO et al., 2010). Assim, como identificado nas propriedades particulares do entorno e do AAC, o uso de 2,4-D é frequente e poderia ter sido detectado mesmo que em quantidade muito inferior ao limite permitido, uma vez que o equipamento utilizado para a avaliação das amostras possui resolução ampla, o que pode ser explicado pela diferença nas condições ambientais.

A exposição de piava (Leporinus obtusidens) a 2,4-D na concentração de 1 ou $10 \mathrm{mg} \mathrm{L}^{-1}$ indicou alterações na atividade da acetilcolinesterase no cérebro e músculos e alguns parâmetros metabólicos do sangue e tecidos (FONSECA et al., 2008). Nas orientações para qualidade de água para consumo a Organização Mundial de Saúde preconizava que a associação sugerida entre o 2,4-D e duas formas de câncer em humanos foi obtida em estudos inconclusivos (OMS, 2011). Contudo, em 2015 a Agência Internacional de Pesquisa sobre Câncer, da OMS, emitiu nota reclassificando o 2,4-D como possivelmente carcinogênico para humanos com base na forte evidência de que induza ao estresse oxidativo e moderada evidência de que cause imunossupressão (IARC, 2015).

O ingrediente ativo protioconazol faz parte do grupo químico triazolintione, vendido na forma composta com o trifloxistrobina, ambos fungicidas de ação sistêmica, classificados como extremamente tóxicos. É considerado muito perigoso ao meio ambiente (classe II), tendo baixa solubilidade em água e alta persistência no solo.

A escolha do protioconazol como alvo deste estudo foi feita com base na identificação de sua utilização em propriedades da região. Além disso, as normativas não apresentam valores de referência para a presença do protioconazol em água para consumo humano, com exceção da legislação da União Europeia que estabelece parâmetro único para todo e qualquer biocida encontrado na água. Soma-se a isto a escassez de relatos sobre estudos para verificação da presença deste ingrediente ativo em água e poucas informações 
acerca de efeitos para a saúde humana e meio ambiente. O site da Universidade de Hertfordshire apresenta, em seu banco de dados sobre as propriedades dos pesticidas, informações gerais sobre o protioconazol indicando a possibilidade de causar efeitos sobre o desenvolvimento e a reprodução, ser possivelmente tóxico para fígado e rim e possível causador de sensibilidade na pele (PPDB, 2015).

A legislação da União Europeia (UE, 1998) é uma das mais restritivas quanto à presença de agrotóxicos em água. O resultado das análises da água dos mananciais indicou que dentro do intervalo de medição do equipamento não foi detectada a presença dos agroquímicos, sendo que este é 100 vezes inferior ao limite estabelecido pela UE. Assim, se houver a presença destes agroquímicos na água dos mananciais avaliados é muito pequena e, possivelmente, não causaria problemas à saúde humana e ao meio ambiente.

Entretanto, muito pouco se sabe sobre os efeitos da exposição a baixas concentrações de agrotóxicos para a saúde humana e para o ambiente. Neste sentido, o uso dos agrotóxicos deve ser feito observando-se o princípio da precaução segundo o qual ações antecipatórias são tomadas levando-se em conta os riscos para a saúde humana e para o meio ambiente. O uso de princípios ativos menos tóxicos pode ser uma alternativa para reduzir riscos ambientais, como proposto por Silveira e Antoniosi Filho (2013).

Nos rios Juba e Sepotuba, a coleta a montante foi tomada no ponto de chegada de suas águas à área do AAC e a jusante ao final. O objetivo desta distribuição dos pontos de coleta foi avaliar a influência das atividades no AAC e de seu entorno na qualidade da água. Os resultados obtidos indicam que os empreendimentos implantados nas áreas mais altas dos rios Juba e Sepotuba e as atividades na área do AAC não estão contribuindo para a contaminação de suas águas.

No ribeirão Tarumã a coleta a montante foi realizada próximo ao encontro de seu principal tributário à direita, que conjuga as águas dos córregos Lambari e Russo situados na área do AAC, ao córrego Tarumã, que percorre propriedades particulares no entorno da Serra de Tapirapuã, e a de jusante foi tomada próximo ao seu encontro com o rio Sepotuba. Assim, os resultados indicam que as atividades desenvolvidas na parte alta quando ainda é conhecido com córrego Tarumã e seus tributários Lambari e Russo não estão promovendo a contaminação da água.

O vazio sanitário para a cultura da soja no estado de Mato Grosso em 2015 teve início em primeiro de junho. Na data da coleta de água, o processo de colheita estava sendo finalizado. Assim, caso houvesse algum tipo de contaminação residual por protioconazol, poderia ter sido detectada na análise, o que não ocorreu.

Além disso, no dia anterior à coleta foi registrado o volume de $50 \mathrm{~mm}$ de chuva na região. A ocorrência de chuva em dias que antecedem coletas para este tipo de estudo pode favorecer a detecção de agrotóxicos em virtude do carreamento de partículas de solo promovido pelo escoamento superficial.

$\mathrm{Na}$ agricultura tecnificada, como verificado na parte alta dos mananciais em questão, faz-se o uso de uma grande variedade de agroquímicos. Em diversos estudos foram encontrados diversos agrotóxicos, em concentrações variadas, o que pode ser um indicativo de que os mananciais avaliados não estejam contaminados com outros agroquímicos. 
Outro aspecto importante a se destacar é que a ausência de 2,4-D e protioconazol na água dos mananciais superficiais não implica, necessariamente, que as águas subterrâneas não estejam contaminadas. Neste sentido, a avaliação da qualidade das águas subterrâneas quanto à presença de agrotóxicos pode ser o foco de novos estudos na área do AAC.

Neste caso, o monitoramento da qualidade da água superficial pode auxiliar na manutenção da qualidade ambiental e, consequentemente, na qualidade de vida da população que depende desses recursos, como a do AAC.

\section{CONCLUSÃO}

Os resultados encontrados indicam que as atividades desenvolvidas no Assentamento Antônio Conselheiro e no seu entorno, provavelmente, não estejam promovendo a contaminação das águas superficiais, por 2,4-D e protioconazol, nos trechos avaliados.

A contaminação de águas superficiais e subterrâneas em decorrência do uso de agrotóxicos na agricultura vem sendo detectada em estudos realizados em diversas regiões do país e do mundo. Entretanto, ações de conscientização dos agricultores quanto ao uso de práticas adequadas para minimizar os efeitos do uso de agrotóxicos não têm alcançado o seu objetivo. Neste sentido, a fiscalização e orientação dos envolvidos no processo são fundamentais, pois só assim os impactos negativos do uso dos agrotóxicos podem ser reduzidos.

\section{REFERÊNCIAS}

BRASIL. Ciência e Tecnologia. Saiba mais sobre a água, consumo consciente e recursos hídricos no Brasil. Portal Brasil, 17 set. 2010 .

BRASIL. Lei no 2,914, de 12 de dezembro de 2011. Dispõe sobre os procedimentos de controle e de vigilância da qualidade da água para consumo humano e seu padrão de potabilidade. Brasília: DOU, 14 dez. 2011. Seção 1, n.239, p.39-46.

BRASIL. Ministério de Meio Ambiente. Agrotóxicos. 2015.

BRASIL. Resolução do Conselho Nacional de Meio Ambiente no 357, de 17 de março de 2005. Dispõe sobre a classificação dos corpos de água e diretrizes ambientais para o seu enquadramento, bem como estabelece as condições e padrões de lançamento de efluentes, e dá outras providências. Brasília: DOU, 18 mar. 2005. Seção 1, n.53, p.58-63.

CERDEIRA, A. L.; PESSOA, M. C. P. Y.; BONATO, P. S.; QUEIROZ, R. H. C.; LANCHOTE, V. L.. Metodologia analítica de resíduo do herbicida 2,4-d (ácido 2,4-diclorofenoxiacético) em amostras de água em área de cultivo de cana-de-açúcar. Pesticidas: Revista de Ecotoxicologia e Meio Ambiente, v.12, p.99-110, 2002.

DALLACORT, R.; MOREIRA, P. S. P.; INOUE, M. H.; SILVA, D. J.; CARVALHO, I. F.; SANTOS, C.. Wind speed and direction characterization in Tangará da Serra, Mato Grosso State,
Brazil. Revista Brasileira de Meteorologia, São José dos Campos, v.25, n.3, p.359-364, 2010.

DORES, E. F. G.; DE-LAMONICA-FREIRE, E. M.. Contaminação do ambiente aquático por pesticidas. Estudo de caso: águas usadas para consumo humano em Primavera do Leste, Mato Grosso - Análise preliminar. Química Nova, Rio de Janeiro, v.24, n.1, p.27-36, 2001.

EPA. Environmental Protection Agency. Drinking water contaminants. 2014.

FONSECA, M. B., GLUSCZACK, L., MORAES, B. S., MENEZES, C. C., PRETTO, A., TIERNO, M. A., ZANELLA, R., GONÇALVES, F. F. \& LORO, V. L. The 2,4-D herbicide effects on acetylcholinesterase activity and metabolic parameters of piava freshwater (Leporinus obtusidens). Ecotoxicology and Environmental Safety, v.69, n.3, p.416-420, 2008.

GASPARINI, M. F.; FREITAS, C. M. Trabalho rural, saúde e ambiente: as narrativas dos produtores de flor frente aos riscos socioambientais. Ambiente \& Sociedade, São Paulo, v.16, n.3, p.23-44, 2013

GRIZA, F. T.; ORTIZ, K. S.; GEREMIAS, D.. Avaliação da contaminação por organofosforados em águas superficiais no município de Rondinha - Rio Grande do Sul. Química Nova, São Paulo, v.31, n.7, p.1631-1635, 2008.

HC. Health Canada. 2,4-Dichlorophenoxyacetic Acid. Environmental and Workplace Health. 2009. 
IARC. International Agency for Research on Cancer. OMS. IARC Monographs evaluate DDT, lindane, and 2,4-D. Press Release n. 236. Lyon: 2015.

IBGE. Instituto Brasileiro de Geografia e Estatística. Mapa de Solos do Brasil. Escala 1:5.000.000. Rio de Janeiro: 2011.

IBGE. Instituto Brasileiro de Geografia e Estatística. Mapa de Biomas do Brasil: primeira aproximação. Escala 1:5.000.000. Rio de janeiro: 3 ed. 2004a.

IBGE. Instituto Brasileiro de Geografia e Estatística. Mapa de Vegetação do Brasil. Escala 1:5.000.000. Rio de janeiro: 3 ed. 2004b.

MOREIRA, J. C.; JACOB, S. C.; PERES, F.; LIMA, J. S.; MEYER, A.; OLIVEIRA-SILVA, J. J.; SARCINELLI, P. N.; BATISTA, D. F.; EGLER, M.; FARIA, M. V. C.; ARAÚJO, A. J.; KUBOTA, A. H.; SOARES, M. O.; ALVES, S. R.; MOURA, C. M.; CURI, R.. Avaliação integrada do impacto do uso de agrotóxicos sobre a saúde humana em uma comunidade agrícola de Nova Friburgo, RJ. Ciência \& Saúde Coletiva, Rio de Janeiro, v.7, p.299-311, 2002.

MOREIRA, J. C.; PERES, F.; SIMÕES, A. C.; PIGNATI, W. A.; DORES, E. C.; VIERA, S. N.; STRÜSSMANN, C.; MOTT, T..
Contaminação de águas superficiais e de chuva por agrotóxicos em uma região do estado do Mato Grosso. Ciência \& Saúde Coletiva, Rio de Janeiro, v.17, n.6, p.15571568, 2012.

OMS. Organização Mundial de Saúde. Guidelines for drinking-water quality. 4 ed. Geneva: WHO Press, 2011.

PINHEIRO, A.; SILVA, M. R.; KRAISCH, R.. Presença de pesticidas em águas superficiais e subterrâneas na bacia do Itajaí, SC. Rega, v.7, n.2, p.17-26, 2010.

PPDB. Pesticide Properties Data Base. University of Hertfordshire. General information for prothioconazole. 2015.

SILVEIRA, A. V. T.; ANTONIOSI FILHO, N. R.. Proposta de alternativas menos tóxicas para ingredientes ativos de agrotóxicos no mercado brasileiro. Pesticidas: Revista de Ecotoxicologia e Meio Ambiente, Curitiba, v.23, p.11-24, 2013.

UE. União Europeia. Diretiva 98/83/CE do Conselho, de 3 de novembro de 1998. Relativa à qualidade da água para consumo humano. Jornal Oficial das Comunidades Europeias, L 330, 5 Dez 1998. 